\title{
Percepções de Valores Organizacionais Declarados de uma Organização Educacional
}

\author{
Ana Luiza Gonçalves da Silva \\ Narbal Silva \\ Universidade Federal de Santa Catarina
}

\begin{abstract}
RESUMO
Os valores declarados têm função relevante, pois orientam no alcance dos objetivos das organizações e o direcionamento que estas almejam acerca do comportamento das pessoas. Além disso, determinam orientação, vínculo e o comprometimento dos colaboradores com a organização, de maneira que eles desempenhem as tarefas que lhes são atribuídas. Esta pesquisa teve como objetivo identificar as percepções dos colaboradores de diferentes níveis hierárquicos acerca das declarações de valores da organização na qual trabalham. O nível de mensuração utilizado na análise dos dados foi predominantemente nominal e a amostra foi composta por 12 colaboradores, o que correspondeu a $100 \%$ do nível estratégico, 33,33\% do nível tático e 12,5\% do nível operacional. As fontes de informação foram coletadas de maneira indireta, por meio de entrevistas, do planejamento estratégico e de regimentos internos. As verbalizações dos participantes entrevistados possibilitaram identificar as percepções nos diferentes níveis hierárquicos referentes às dimensões: significado, pertinência, função, clareza, coerência, incoerência e importância. Por meio do estudo foi possível demonstrar que os colaboradores, independente do nível hierárquico em que se encontram, não têm consciência da importância dos valores organizacionais e que, muitos deles, não sabem ao menos o que são valores organizacionais e quais as suas funções para a organização.
\end{abstract}

Palavras-chave: valores organizacionais; declaração de valores organizacionais; cultura organizacional; percepções; níveis hierárquicos.

\section{ABSTRACT \\ Perceptions of Espoused Values on an Educational Organization}

The values declared by organizations have an important role since they orient the organizations to fulfill their objectives and guide peoples' behavior towards them. Their main function is to build a bond and set a commitment between the employees and the organization so that they can stay within it and fulfill the tasks they are assigned. The objective of this research was to identify the workers' perception of the different hierarchical levels on the value declarations in the institution where they work. The data was collected through direct and indirect source of information, through interviews and institutional documents. The interviewed participants' verbalizations made it possible to identify the perceptions in the different hierarchical levels concerning the following dimensions: meaning, appropriateness, function, understanding, coherence, incoherence and importance. These dimensions were not found in any literature. They will allow future researchers to evaluate the different perceptions concerning organizational values. The study showed that the workers, whatever their hierarchical level might be, were not aware of the importance of the organizational values and most of them didn't even know what those values are and what functions they play in the organization.

Keywords: organizational values; espoused organizational values; organizational culture; perceptions; hierarchical levels.

Assim como os seres humanos, as organizações também encontram exigências que precisam ser satisfeitas para garantir sua sobrevivência. Para Tamayo (1998), as formas de pensar, de refletir, de solucionar problemas de comunicação com os colegas e com os gerentes, de analisar as expectativas próprias e as dos outros, são fenômenos influenciados pelo modo como os valores são percebidos nas organizações de trabalho. A percepção dos colaboradores acerca de como os valores organizacionais declarados são difundidos e compartilhados parece fundamental para compreender e avaliar as maneiras dos colaboradores resolverem os 
problemas com que se deparam. Isto porque, os valores organizacionais representam princípios e crenças estabelecidos hierarquicamente, relativos aos padrões de comportamento almejados, que norteiam a vida da organização e das pessoas e estão a serviço de interesses tanto individuais quanto coletivos.

A comunicação dos valores organizacionais pode ocorrer de diversas maneiras, dentre elas por meio de: a) histórias, sagas, lendas e folclores; b) heróis e mitos (pessoas importantes para a organização, que servem de modelo para a ação dos demais integrantes); c) ritos e cerimônias (maneiras de selecionar, de treinar, as festas, as reuniões, as promoções); d) linguagens, símbolos, gestos e códigos; e) artefatos físicos (distribuição dos móveis, dos prédios, dos setores; e f) programas de ambientação e de outras práticas organizacionais, tais como reuniões, seminários, conferências, boletins informativos, avaliação de desempenho, entre outros (Oliveira, 2001). A maneira como os colaboradores percebem os valores organizacionais também está relacionada com a inserção desses no nível hierárquico da organização. Isso porque as informações são disseminadas de diferentes maneiras, dependendo do nível da estrutura organizacional onde estão sendo direcionadas (Litterer, 1977).

Os valores organizacionais podem ser avaliados sob duas perspectivas de percepção: a dos valores reais ou ideais. Para Tamayo (1996), o nível real faz referência aos valores existentes concretamente na organização, segundo a percepção da força de trabalho. Ainda para o autor, os valores reais guiam a vida organizacional, especialmente no que diz respeito às decisões e na definição de políticas. Já o nível ideal se refere aos valores que as pessoas percebem como os que deveriam orientar os comportamentos dos participantes na organização. Esses valores são idealizados e racionalizados pelos dirigentes das organizações de trabalho, e até muitas vezes divulgados. Porém, na prática, nem sempre são percebidos pelos colaboradores como valores que de fato orientam as decisões e as práticas dos gestores organizacionais. Contudo, quando os colaboradores conhecem os valores declarados nas organizações e os identificam na prática organizacional, é mais provável que seus comportamentos sejam coerentes com tais valores (Sanches, 1992).

Para estudar os valores organizacionais, três abordagens têm sido identificadas na literatura: a) o estudo dos valores, por meio dos documentos oficiais da organização (como o seu planejamento, suas portarias, seus relatórios); b) o estabelecimento de uma média dos valores individuais dos membros da organização; e c) a avaliação das percepções compartilhadas dos colaboradores da organização por meio de questionários ou entrevistas, como, por exemplo, o Inventário de Valores Organizacionais. Como limitações de cada abordagem, a primeira não considera que as pessoas que produzem os documentos oficiais são principalmente as que compõem o nível hierárquico estratégico da organização e, assim, os valores declarados seriam os valores típicos desse nível. Também não são levadas em conta, possíveis diferenças entre os valores organizacionais nos diferentes níveis hierárquicos. A segunda perspectiva não contempla que os valores individuais de cada colaborador podem ser muito divergentes, o que dificultaria a obtenção e a fidedignidade dos resultados obtidos. Por último, a terceira abordagem, baseada na utilização de escalas fechadas, restringe as análises e os valores descritos na escala nem sempre refletem os valores da organização. Ter clareza das abordagens presentes na literatura ao estudar os valores organizacionais e as limitações de cada uma delas, possibilita a realização de estudos que tentem minimizar as limitações de cada abordagem.

Tamayo (1998) também acrescenta que os valores organizacionais são determinantes do comportamento humano nas organizações. Para o autor, o comportamento humano nas organizações é determinado pelo contexto em que ele acontece e depende da percepção e da avaliação que os colaboradores fazem dos valores organizacionais. Portanto, se os valores declarados forem percebidos como incongruentes com os valores praticados, especialmente o dos gestores, é de se esperar que os comportamentos dos colaboradores tendam a ser incompatíveis com os valores declarados na organização. A percepção constitui fenômeno psicológico relevante no modo como comportamentos, eventos e situações são compreendidos. Em razão disto, entender os significados conferidos pelos colaboradores aos seus processos perceptivos da dimensão real dos valores organizacionais pressupõe ampliar a base de compreensão do modo como os gestores orientam o comportamento de seus colaboradores.

Para Matos (1996) é necessária consistência interior para que ocorra coerência externa nas ações humanas nas organizações. Por isso a formação de uma concepção filosófica baseada em valores explícitos é o alicerce para a construção de uma cultura "sadia". Nesse sentido, quando a disseminação dos valores, nos níveis hierárquicos é coerente com a prática, os colaboradores apreendem e passam a confiar nos valores declarados. Caso contrário, se os valores organizacionais declarados não forem coerentes com os com- 
portamentos, os colaboradores perceberão a incongruência e a relação de envolvimento passa a não ser favorável para o alcance dos objetivos da organização.

Em estudo realizado por Jacometti e Silva (2003) por meio de entrevistas e de análise documental, demonstraram incongruência entre os valores e as crenças, percebidos e praticados, e, em decorrência, inconsistências entre os objetivos do nível estratégico e tático de uma organização de ensino. Os resultados da pesquisa demonstraram que os valores e crenças são fatores preponderantes para a definição de objetivos e que as percepções diferenciadas desencadeiam diversos "pontos de vista" e disputas internas nas organizações. Tamayo (1998)complementa que a análise dos valores percebidos pelos colaboradores como característicos das organizações revela a maneira como os objetivos gerais da mesma são captados pelos seus membros e serve de base para o planejamento de mudanças no clima e na cultura organizacionais.

Nas organizações, a cultura é percebida de maneira diferenciada, em virtude, principalmente, do processo de socialização de cada indivíduo e das informações organizacionais que cada colaborador tem acesso. Porém, algumas características são marcantes e particulares da cultura organizacional e tendem a ser percebidas de modo compartilhado. Segundo Robbins (2002) em uma cultura denominada "forte", os valores da organização são intensamente mantidos e partilhados. Quanto mais os colaboradores aceitarem e se comprometerem com os valores organizacionais, mais "forte" é a cultura da organização, o que possibilita criar um clima interno de grande controle comportamental. Para Mazzucco e Rocha (2001) um alto nível de homogeneidade na percepção dos valores leva cada colaborador a exercer a autoridade de maneira igual e, dessa maneira, é desnecessário haver controle externo. Nesse sentido, o fato dos valores organizacionais serem compartilhados de maneira homogênea pelos colaboradores parece ser importante para construir uma cultura organizacional coesa em que a lealdade e o comprometimento sejam expressos nos comportamentos dos colaboradores.

Outro aspecto também a ser observado quando se estuda valores organizacionais, além da verificação de consistência entre o que é declarado e o que efetivamente acontece, é a relação entre os valores individuais e os organizacionais. Para Loiola, Bastos, Queiroz e Silva (2004), a integração entre os propósitos individuais/grupais e os organizacionais é marcada por tensões, as quais modelam os "cursos de ação" e os processos organizacionais. Tamayo (1996) acrescenta que os valores organizacionais devem ser constituídos por elementos que devem abranger desde as necessidades biológicas dos indivíduos até as necessidades referentes à sobrevivência e ao bem-estar da organização. A respeito deste assunto, Stinglhamber, Bentein e Vandenberghe (2004) demonstraram em uma pesquisa realizada com 200 colaboradores de 10 organizações, por meio de questionários, que o compromisso dos colaboradores com a organização geralmente é explicado pelos valores da organização e a congruência do valor pessoa-organização. Também nessa direção, Freitas (1991) se reporta à pesquisa realizada com 1500 administradores americanos, onde foi demonstrado que a concordância dos valores pessoais com os valores organizacionais possibilita uma experiência de forte sentimento de sucesso nos administradores, o que aumenta o desejo de trabalhar na organização, além de criar uma relação de confiança de que esses colaboradores continuarão na organização. Por isso, os valores organizacionais declarados têm um papel importante nas organizações, pois podem facilitar o compromisso dos colaboradores com a organização, caso os valores pessoais dos colaboradores sejam semelhantes aos organizacionais, além de influenciarem na qualidade de vida do colaborador.

As percepções dos colaboradores a respeito da organização onde trabalham têm implicações na qualidade de suas relações e, por consequência, na qualidade de sua vida dentro da organização. Para Borges e Yamamoto (2004) a realidade não está pronta e acabada; ela é construída ou criada pelo sujeito a partir dos seus pressupostos, ideias, modelos mentais e estruturas cognitivas, que organizam o conhecimento dessa realidade. Ou seja, as interpretações que os colaboradores fazem da organização, das situações nela vivenciadas e das estratégias cognitivas que utilizam para relacionar-se na organização, fazem com que essa realidade seja singular e repercuta na maneira como o sujeito interage no contexto organizacional. A pesquisa realizada por Borges e cols. (2002) em três hospitais universitários do Rio Grande do Norte, com 205 profissionais da saúde, por meio de questionários, demonstrou a relação entre os valores organizacionais e a incidência da síndrome de burnout. Foi evidenciado, por meio da aplicação de análise de regressão, que a síndrome de burnout apresenta uma relação inversamente proporcional aos valores organizacionais, ou seja, quando os valores organizacionais não são aceitos ou são incongruentes com as práticas organizacionais, os colaboradores estão mais propensos ao desenvolvimento de doenças, no caso desse estudo, a sín- 
drome de burnout. Os resultados da pesquisa realizada por Mendes (2004) também demonstraram a relação entre valores organizacionais e a qualidade de vida no trabalho. A autora demonstrou por meio da utilização do Inventário de Valores Organizacionais, que as culturas mais favoráveis ao prazer dos colaboradores são aquelas que enfatizam os seguintes valores: liberdade de escolha, autonomia, independência dos indivíduos e as relações de troca. Essas características possibilitam aos indivíduos ajustarem suas necessidades pessoais à realidade organizacional. Para a autora, é importante ressaltar que os valores organizacionais exercem um papel fundamental na construção de estratégias de enfrentamento do sofrimento. Dependendo do quanto os valores facilitam os colaboradores na construção de soluções eficazes de compromisso para mediar os conflitos que vivenciam, possibilitam ou não às organizações maior probabilidade de obterem sucesso e de manterem seus colaboradores comprometidos e produtivos. Portanto, o estudo dos valores organizacionais adquire relevância, uma vez que, embora sejam freqüentemente citados na literatura de cultura organizacional, ainda são necessários estudos empíricos que possibilitem ampliar a visibilidade do fenômeno. (Tamayo, 1996).

Tamayo e cols (2000) ao estudar os a percepção dos valores organizacionais. $\mathrm{O}$ autor propõe que os valores não são definidos a priori, e que podem ser classificados em uma hierarquia não fixa, que varia de organização para organização. Nesse estudo, os autores validam um instrumento denominado Inventário de Valores Organizacionais (IVO) que identifica dimensões que avaliam as prioridades axiológicas da organização, a sua base motivacional predominante e as percepções dos colaboradores em relação a estas prioridades. A identificação do colaborador em relação a esta percepção possibilita avaliar a relação que o colaborador tem com a organização e o comportamento que assume diante dessa representação cognitiva.

Estudar a cultura, e em especial os valores organizacionais, possibilita entender a maneira singular como as pessoas se relacionam com os seus ambientes externo e interno. No entanto, os estudos encontrados para avaliar a cultura e o seu principal elemento, os valores organizacionais não podem ser reduzidos a utilização de escalas pré-definidas, como os questionários e escalas validadas. Ferreira e cols. (2002) fazem referência a somente dois instrumentos legitimamente brasileiros para avaliação da cultura e dos valores organizacionais: a Escala para Medida e Validação da Cultura Organizacional, desenvolvida pelos autores Gomide Júnior e Martins (1997) e o Inventário de Valores Organizacionais, desenvolvido pelos autores Tamayo e Gondim (1996). Em contrapartida, os estudos referentes à cultura e valores organizacionais que contemplem os níveis de mensuração nominal e ordinal, possibilitam a análise descritiva dos fenômenos em estudo. Uma perspectiva desse tipo implica reconhecer as especificidades de cada organização.

Para a finalidade deste estudo, foram encontrados, em números reduzidos, pesquisas onde foram utilizados os níveis de mensuração nominal e/ou ordinal na análise da cultura e valores organizacionais, entre eles, Silva (2001), Jacometti e Silva (2003) e Guarido Filho e Silva (2001). Pupak (2003) ao concluir sua pesquisa, Valores organizacionais: a cultura da excelência, identificou uma lacuna na literatura a respeito do assunto e recomendou que sejam realizadas pesquisas sobre o fenômeno que verifiquem as percepções dos colaboradores sobre os valores organizacionais e levem em consideração os diferentes grupos de colaboradores.

Até aqui, foram abordadas a percepções que as pessoas têm do contexto das organizações, o modo como a estrutura repercute nas interações humanas, na distribuição das informações e suas consequências percepções dos colaboradores. Também foi apresentado, o conceito de cultura organizacional, os seus elementos principais e respectivos níveis. Nessa descrição, os valores organizacionais foram concebidos como elementos centrais da cultura de uma organização. Além disto, também foram elencados alguns estudos que demonstram a as relações entre percepções de valores organizacionais e qualidade das relações com o meio interno e externo da organização. Também foi evidenciado por meio de estudos, que o modo como os valores organizacionais são percebidos, proporcionam indícios a respeito da aprendizagem dos objetivos estratégicos da organização. Além disto, foi demonstrado que os valores organizacionais declarados têm uma função importante, pois podem facilitar ou restringir o comprometimento e a qualidade de vida dos colaboradores. Por fim, foram destacados os modos como estão sendo processados os estudos sobre valores organizacionais e a limitação de cada abordagem. Em razão de todas estas evidências é possível concluir que a produção de conhecimentos que permitam responder quais são as percepções dos colaboradores nos diferentes níveis hierárquicos a respeito das declarações de valores da organização na qual trabalham se constitui em estudo relevante do ponto de vista social e científico. 


\section{MÉTODO}

Os participantes da pesquisa foram colaboradores do nível estratégico, tático e operacional de uma organização do ramo da educação, sendo que a amostra foi composta por $100 \%$ do nível estratégico, $33,33 \%$ do nível tático e $12,5 \%$ do nível operacional, ao se considerar o número total de colaboradores por nível hierárquico e os critérios amostrais.

Como critérios da construção da amostra os colaboradores foram divididos em uma amostra por estratos, na qual houve a divisão dos colaboradores em três grupos: estratégico, tático e operacional. Em seguida, foi realizada a escolha dos participantes dos três grupos por meio de uma amostra aleatória simples. Outro critério considerado foi o tempo de trabalho na organização, que deveria ser de pelo menos um ano e sem transferência de setor, o que leva em consideração o processo de socialização secundária, ou mais especificamente, a socialização organizacional.

No recorte feito à decomposição das variáveis de análise foram considerados dois aspectos: a percepção dos colaboradores e os valores declarados por meio de documentos.

As fontes de informação foram coletadas de maneira indireta, por meio de entrevistas, do Planejamento Estratégico e de Regimentos Internos. A análise dos documentos relativos ao planejamento estratégico e aos regimentos teve como finalidade identificar os valores declarados na organização pesquisada. Foram considerados como valores declarados, os citados nos documentos analisados de maneira explícita enquanto valores da organização. As entrevistas, que tiveram como objetivo identificar as percepções dos colaboradores acerca dos valores organizacionais declarados, foram realizadas individualmente, em uma sala reservada na organização pesquisada, em horário previamente marcado e durante o horário de trabalho do colaborador.

A decomposição do fenômeno perceptivo por meio dos entrevistados ocorreu em dois níveis. O primeiro reconhecer os estímulos, que consideram os aspectos relacionados à maneira de perceber, como visão, audição e tato. E o segundo, interpretar os estímulos relacionados ao sentido ou ao juízo que os colaboradores atribuem aos valores que percebem presentes na organização. As dimensões significado, pertinência, função, clareza, coerência, incoerência e importância foram criadas a partir das referências Abbagnano (1999), Weiszflog (1998) e Wilson e Keil (2001), com o propósito de ampliar as possibilidades de estudo do fenômeno percepção dos valores organizacionais. As dimensões foram identificadas A seguir são descritas as definições conceituais das dimensões referidas: 1) Significado - sentido, valor, o que as coisas querem dizer ou representam. Conexão entre o signo e seu objeto; 2) Pertinência - próprio, apropriado. Quando os elementos fazem parte do mesmo conjunto; 3) Função - que representa ou serve para representar; desempenha um papel, uma atribuição, uma função de. posição, atribuição de natureza moral, jurídica, técnica; 4) Clareza - qualidade do que percebe bem, transparência. Inteligível, nítido, límpido; 5) Coerência estado ou qualidade de coerente, que tem nexo, lógico. Compatibilidade, que designa o caráter de não contradição; 6) Incoerência - estado ou qualidade de incoerente, discordante, desconexo, ilógico, contraditório; 7) Importância - autoridade, consideração, crédito.

Os valores declarados por meio de documentos na organização pesquisada são os seguintes: Transparência nas Ações, Qualidade nas Ações Educacionais, Parcerias, Integridade nas Ações e Relações, Crescimento Sustentável, Responsabilidade Social, Formação para Cidadania, Inovação e Tecnologia, Valorização das pessoas, Comprometimento com a aprendizagem e Credibilidade. Esses valores foram extraídos de documentos oficiais da organização. É importante salientar que nos documentos pesquisados não foram conferidos significados aos valores declarados.

Ao considerar a necessidade de limitar o número de perguntas do instrumento de coleta de dados do tipo roteiro de entrevista, os valores foram agrupados em quatro grupos, qualidade nas ações educacionais, transparência nas ações, responsabilidade social e por fim, inovação e tecnologia.

As perguntas utilizadas nas entrevistas foram às mesmas para os quatro valores pesquisados, sendo elas: a) O que você entende por NOME DO VALOR? b) Quais as relações entre NOME DO VALOR e a missão da organização? c) Quais as consequências para a sociedade, caso os colaboradores da organização desenvolvam ações educacionais com NOME DO VALOR? d) Quais as relações entre NOME DO VALOR e os serviços prestados pela organização? e) Descreva situações em que você identifica ou identificou comportamentos relacionados a NOME DO VALOR. f) Descreva situações em que você identifica ou identificou comportamentos que não estavam relacionados a NOME DO VALOR g) Se não houvesse NOME DO VALOR na organização o que ocorreria?

$O$ instrumento para a coleta dos dados foi desenvolvido também considerando os significados conferidos as dimensões de percepção, transformando-os 
em indicadores operacionais da percepção. São eles: 1) Significado: Esse indicador identificou o que o valor expressa (dá a entender) para cada funcionário; 2) Pertinência: Esse indicador avaliou se o valor é percebido como adequado (apropriado) ou inadequado (impróprio) considerando a missão da organização; 3 ) Função: Nesse indicador foi avaliado se o valor é percebido como tendo atribuições (desempenha papéis) ou não tendo atribuições na organização; 4) Clareza: Nesse indicador foi avaliado se o valor é percebido de modo inteligível (que é compreendido bem) ou ambíguo (que pode tomar em mais de um sentido); 5) Coerência/incoerência: Nesse indicador foi avaliado se o valor é percebido de maneira contraditória ou não, em políticas, programas e comportamentos das pessoas na organização; 6) Importância: Nesse indicador foi avaliado se o valor é percebido como importante (necessário) ou irrelevante (desnecessário).

O instrumento de coleta de dados foi testado em duas aplicações piloto para a verificação de possíveis problemas de compreensão, o que possibilitou o aprimoramento do mesmo. A coleta dos dados obedeceu ao previsto na Resolução CNS 196 de 10/10/1996 Diretrizes e normas regulamentadoras de pesquisa com seres humanos. $\mathrm{O}$ estudo iniciou com a análise dos documentos e posteriormente com a realização das entrevistas. Foram realizadas doze entrevistas somente na presença do pesquisador e do funcionário participante da pesquisa.

Após a realização das entrevistas, foram realizadas anotações como o registro de interrupções, dificuldades para responder o instrumento, dúvidas, tempo de duração da aplicação e quaisquer outros acontecimentos não previstos pelo pesquisador.

\section{RESULTADOS E CONCLUSÕES}

As verbalizações dos participantes entrevistados possibilitaram identificar as percepções dos mesmos nos diferentes níveis hierárquicos acerca das dimensões: significado, pertinência, função, clareza, coerência, incoerência e importância. Uma das percepções identificadas é a de que os participantes desconheciam os valores organizacionais da organização. Nenhum dos entrevistados conseguiu citar algum dos valores declarados pela organização. Este aspecto é significativo, já que os valores têm a propriedade de orientar os comportamentos das pessoas nas organizações (Senge, 1999).

Outro aspecto relevante e que necessita ser discutido pelos dirigentes da organização é a percepção dos colaboradores sobre a ausência do valor valorização das pessoas. Tal valor foi o mais citado pelos participantes como ausente na práxis da organização. Paradoxalmente, na organização são prestados serviços na área da educação, e, em decorrência, os colaboradores, em todos os níveis hierárquicos, interagem diariamente com clientes externos. Tal fato não constitui contradição com a percepção de inexistência da valorização de seus colaboradores por meio de políticas e práticas organizacionais? Como é possível alcançar e conciliar rentabilidade, tão almejada pelos dirigentes e a ausência de percepção de valorização por parte dos colaboradores? No caso da organização pesquisada, percepção de pouca responsabilidade social com os clientes internos vai de encontro a concepção de construção de conduta ética e de qualidade nas relações com os colaboradores (Nassar, 2006).

Ao se considerar as percepções das dimensões dos valores organizacionais declarados, foi possível identificar ausência de significado destes valores. Como já mencionado anteriormente, não existe nos documentos pesquisados, uma descrição dos significados dos valores organizacionais declarados. Também nos discursos dos participantes ficou clara a ausência de homogeneidade dos significados conferidos aos valores. Segundo Schein (1987), quando, por ausência de definição, os valores esposados não são compartilhados, as distintas maneiras de perceber geram diferenças nos modos de pensar, sentir e agir nas organizações de trabalho.

De maneira geral, com relação à pertinência dos valores, os participantes consideram que os mesmos estariam relacionados à missão da organização. Somente no valor transparência nas ações é que os participantes tiveram dificuldades de responder a pergunta. Talvez em virtude de ser um valor mais abstrato, por não ter uma representação figurativa, e se constituir no valor mais distante da missão da organização, e que por isto, necessitaria estabelecer relações de natureza mais complexa. Cabe ressaltar que, ao reconhecerem os valores organizacionais declarados nas práticas dos gestores e demais colaboradores da organização, os colaboradores, em geral, tendam a ter comportamentos condizentes com os valores organizacionais (Sanches, 1992).

Com relação à dimensão função dos valores organizacionais declarados, mesmo tendo os pesquisados, em relação a alguns valores como, por exemplo, qualidade nas ações educacionais e transparência nas ações, percepções homogêneas, nem sempre tais compreensões foram vinculadas às funções essenciais 
desses valores. No valor transparência nas ações, a função percebida se relacionou à imagem da organização. Será que os gestores declararam o valor transparência nas ações organizacionais em virtude da preocupação com a imagem projetada na sociedade? Já no caso do valor responsabilidade social, a maioria dos colaboradores pesquisados não conseguiu descrever nenhum tipo de função conferida ao valor. Quando o valor de responsabilidade social é expresso por meio de programas que visam "polir" a imagem da organização traduzindo-se em marketing institucional, os objetivos efetivos de sustentabilidade social ficam distorcidos (Carvalho, 2002).

A dimensão clareza foi à dimensão com percepções mais negativas em todos os valores. O que ficou demonstrado é que os participantes não conseguem relacionar os valores com os serviços prestados pela organização, ou seja, não percebem de modo inteligível o valor. Pelo contrário, ele é percebido de maneira ambígua pelos participantes da pesquisa. Para Terra (1999) um dos papéis essenciais dos gestores nas organizações de trabalho é o de disseminar os valores organizacionais, essencialmente, por meio de seus comportamentos.

As percepções de coerência e incoerência seguiram certo padrão em todos os valores. Os colaboradores conseguiram descrever situações de ocorrência de cada um dos valores, o que indicava a coerência do valor, mas também descreveram situações de ausência do valor, o que indicava incoerência do valor. Assim, comportamentos relacionados aos valores estão sendo percebidos como ocorrendo na organização, mas também existem muitos comportamentos percebidos como contraditórios. Tal fenômeno evidencia as contradições que permeia as relações entre gestores e demais trabalhadores no mundo do trabalho. Não raro, existe um discurso da parte dos gestores que não é sustentado por meio de políticas, programas e comportamentos (Cañete, 2004). Somente no valor responsabilidade social, os colaboradores não conseguiram identificar situações de incoerência do valor. Este valor, considerando todas as suas dimensões, seria o valor percebido como de mais visibilidade na organização. É importante ressaltar que o significado conferido pelos participantes acerca desse valor foi limitado ao estar relacionado somente às ações externas, ou seja, ações direcionadas à comunidade. O que parece prevalecer é o marketing institucional.

A percepção de importância dos valores, conferida pelos participantes da pesquisa estava, de maneira geral, relacionada a dois aspectos: decadência, estag- nação e confusão e a falência da organização. Em princípio, estas percepções podem estar relacionadas a uma forte cobrança por resultados financeiros. Este tipo de cobrança é constante aos colaboradores da organização, e parece, como evidentes repercussões na motivação dos mesmos. Tal fato parece demonstrar ausência de consistência entre valores apregoados e os significados percebidos nos diferentes níveis hierárquicos da organização. A ausência de consistência parece interferir na debilidade de coerência expressa por meio das ações gerenciais (Matos, 1996)

Com relação à percepção dos colaboradores aos valores presentes na organização, os valores mais citados foram os seguintes: qualidade na educação profissional, transparência nas ações e ética nos relacionamentos. Esses três valores estavam presentes nas perguntas do roteiro da entrevista. Metade dos participantes percebeu o valor transparência nas ações como não claro nos serviços prestados pela organização e quase todos os participantes não conseguiram responder a pergunta que verificava a pertinência do valor com relação à missão organizacional. Porém eles descrevem o valor como presente na organização. Essa resposta não seria contraditória? Já com relação ao valor qualidade nas ações educacionais, a maioria dos participantes não percebeu clareza do valor nos serviços prestados pela organização, porém consideraram ele como pertinente ao considerar a missão da organização. É possível que estes valores tenha sido os mais mencionados em virtude de fazerem parte do roteiro da entrevista. Será que os colaboradores da organização entendem o que são valores organizacionais? $\mathrm{O}$ estudo, até aqui, demonstrou que os colaboradores, independente do nível hierárquico não têm consciência da importância dos valores organizacionais e que, muitos deles, não sabes ao menos o que são valores organizacionais e quais as suas funções para a organização.

Os dados da Tabela 1 descrevem quais os valores declarados pela organização e que não são percebidos pelos colaboradores. Uma lista dos valores declarados pela organização foi mostrada para os participantes para facilitar suas respostas. O valor mais citado foi a valorização das pessoas, sendo que um participante do nível estratégico, um do nível tático e um do nível operacional citaram a ausência do valor. Seguidos pelos valores responsabilidade social e formação para a cidadania, descritos por participantes do nível estratégico e tático. Os valores parcerias, integridade nas ações e relações, crescimento sustentável e inovação e tecnologia também forma citados. 
Os participantes do nível operacional tiveram dificuldades para responder a pergunta ao salientarem que não entendem exatamente o significado de alguns valores. Conforme trecho de falas que exemplificam esta afirmação: "O que seria ações e relações? Não sei te dizer." (O2); "Parcerias eu não sei, eu estou por fora, talvez até tenha e eu vou marcar errado, talvez todos os valores existem também. Integridade nas ações e relações não sei o que é, não entendi muito bem". (O6)

Na Tabela 1 estão sistematizados os dados até aqui descritos.

\section{TABELA 1}

Distribuição das percepções dos colaboradores dos níveis hierárquicos estratégico, tático e operacional dos valores que consideram não estarem presentes no dia a dia da organização

\begin{tabular}{|c|c|c|c|c|c|c|c|c|}
\hline \multirow[b]{2}{*}{ 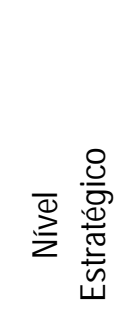 } & Parcerias & $\begin{array}{l}\text { Integridade } \\
\text { nas Ações e } \\
\text { Relações }\end{array}$ & $\begin{array}{l}\text { Crescimento } \\
\text { Sustentável }\end{array}$ & $\begin{array}{l}\text { Resp. } \\
\text { Social }\end{array}$ & $\begin{array}{l}\text { Valorização } \\
\text { das pessoas }\end{array}$ & $\begin{array}{c}\text { Formação } \\
\text { para } \\
\text { Cidadania }\end{array}$ & $\begin{array}{l}\text { Inovação e } \\
\text { Tecnologia }\end{array}$ & $\begin{array}{l}\text { Não soube } \\
\text { responder }\end{array}$ \\
\hline & & & & & $X$ & $X$ & & \\
\hline \multirow{4}{*}{ 离 罚 } & & & & $X$ & & & & \\
\hline & & & & $X$ & $X$ & & & \\
\hline & & & $X$ & & $X$ & & & \\
\hline & $X$ & & & & & & & \\
\hline \multirow{6}{*}{ 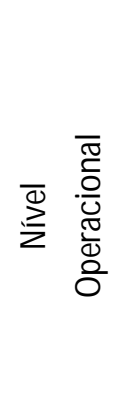 } & & & & & $X$ & & $x$ & \\
\hline & & & & & & & & $X$ \\
\hline & & & & & & & & $X$ \\
\hline & & & & & $X$ & & & $X$ \\
\hline & & & & & & & & $x$ \\
\hline & & $X$ & & & & & & \\
\hline
\end{tabular}

Com relação à pergunta quais os valores declarados que não estavam presentes na organização a percepção dos colaboradores é, no mínimo, preocupante. Os valores transparência nas ações, qualidade nas ações educacionais, comprometimento com a aprendizagem e credibilidade não foram citados pelos participantes da pesquisa. A maioria deles percebeu como valor não presente na organização a valorização das pessoas. Esse tipo de percepção, com certeza, afeta a qualidade de vida no trabalho, a motivação dos colaboradores e o desenvolvimento do trabalho. Para Cañete (2004), muitas contradições permeiam as relações no mundo do trabalho. Existe por parte das empresas um discurso que não corresponde à prática da organização. Para a autora, os dirigentes precisam reconhecer que os colaboradores não apenas querem trabalhar para a organização, mas também desejam pertencer a ela, desejam ser valorizados e recompensados não somente de maneira material, mas também de maneira moral. Esses aspectos estão evidenciados na pesquisa, por meio das percepções de incoerência organizacional e um sentimento de não valorização das pessoas, ou seja, por seus dirigentes. Sendo a organização pesquisada uma organização de ensino e por isso de prestação de serviços, como os colaboradores podem estar motivados e desenvolverem um bom trabalho, seja ele de atendimento a clientes, de elaboração de novos produtos ou de docência, se eles não se sentem valorizados? Este aspecto deve ser rapidamente repensado e elaboradas ações de correção 
para que a organização possa realmente vivenciar os valores que são declarados.

Pelas considerações realizadas até o momento, recomenda-se que os dirigentes repensem e declarem aos colaboradores, quais os significados, as funções e a importância dos valores organizacionais, antes de darem continuidade às mudanças relacionadas à gestão das unidades operativas. Também necessitam refletir sobre o alto turn-over e a desmotivação dos colaboradores em diversas unidades operativas e a relação disto com a ausência de direcionamento do nível estratégico. Isto porque, a análise dos valores percebidos pelos colaboradores como característicos da organização, revela a maneira como os objetivos da mesma são capturados pelos seus membros e expressos em atitudes e comportamentos, servindo de base para o planejamento de mudanças no clima, na cultura e na gestão das dimensões humana e tecnológica da organização (Silva \& Zanelli, 2004).

À guisa de conclusão, este trabalho teve como objetivo identificar as percepções dos participantes dos níveis estratégico, tático e operacional sobre os seguintes valores declarados: qualidade nas ações educacionais, transparência nas ações, responsabilidade social e inovação e tecnologia. A organização pesquisada possui 22 unidades no Estado de Santa Catarina. Assim os resultados deste estudo representam uma amostra de um contexto que é mais amplo. É importante salientar também, a amplitude e a complexidade do tema valores organizacionais, e que por isto, este estudo não pretende esgotar o tema em análise. Em virtude das limitações do estudo, seria relevante que outros estudos do gênero ampliassem o número de unidades estudadas para uma possível intensificação da generalização das dimensões utilizadas neste estudo. Além disso, também seria pertinente que futuros trabalhos realizassem comparações entre os resultados das diferentes unidades da mesma organização e levassem em consideração o perfil dos gestores das unidades. Por fim, cabe ressaltar que as dimensões conceituais definidas e utilizadas no estudo não foram encontradas de modo prévio na literatura. A iniciativa de sistematização e definição das mesmas, portanto, parece constituir em contribuição científica deste trabalho, ainda que de modo incipiente, o que demonstra iniciativa visando o avanço dos estudos referentes aos valores organizacionais. A construção preliminar destas dimensões poderá permitir à futuros pesquisadores o aperfeiçoamento das mesmas, no que se refere a denominações e as respectivas definições operacionais.

\section{REFERÊNCIAS}

Abbagnano, N. (1999). Dicionário de filosofia. São Paulo: Martins Fontes.

Borges, L., e cols. (2002). A síndrome de burnout e os valores organizacionais: Um estudo comparativo em hospitais universitários. Psicologia Reflexão e Crítica, 15(1), 189-200.

Borges, L., \& Alburquerque, F. (2004). Socialização organizacional. Em J. Zanelli, J. Andrade \& A. Bastos (Orgs.), Psicologia, organizações e trabalho no Brasil (pp. 24-62). Porto Alegre: Artmed.

Cañete, I. (2004). Qualidade de vida no trabalho: Muitas definições e inúmeros significados. Em Bitencourt, C. (Org.), Gestão contemporânea de pessoas: Novas práticas, conceitos tradicionais (pp. 387-406). Porto Alegre: Artmed.

Carvalho, R. (2002). Responsabilidade social e empresarial. Trabalho apresentado no XXV Congresso Brasileiro de Ciências da Comunicação, Salvador.

Ferreira, M., e cols. (2002). Desenvolvimento de um instrumento brasileiro para avaliação da cultura organizacional. Estudos de Psicologia (Natal), 7(2), 271-280.

Freitas, M. (1991). Cultura organizacional: Formação, tipologia e impacto. Rio de Janeiro: Makron Books.

Guarido Filho, E., \& Silva, C. (2001). A influência dos valores ambientais e organizacionais sobre a aprendizagem organizacional na indústria alimentícia paranaense. Revista de Administração Contemporânea, 5(2), 33-63.

Jacometti, M., \& Silva, C. (2003). A influencia dos valores, crenças e interesses na definição de objetivos organizacionais: Estudo de caso. Em Associação Nacional de Pós-Graduação e Pesquisa em Administração (Org.), Anais do XVII Encontro Anual dos Programas de Pós- Graduação em Administração (pp. 27-32). Rio de Janeiro: ANPAD.

Litterer, J. (1977). Análise da organização. Em J. Litterer (Org.), Percepção: A questão do que vemos (pp. 65-91). São Paulo: Atlas.

Loiola, E., Bastos, A., Queiroz, N., \& Silva, T. (2004). Dimensões básicas de análise das organizações. Em J. Zanelli, J. Andrade \& A. Bastos (Orgs.), Psicologia, organizações e trabalho no Brasil (pp. 91-144). Porto Alegre: Artmed.

Matos, F. (1996). Cultura e valores no processo de internacionalização das economias: O desafio do humano. Revista Brasileira de Administração, 17, 71-76.

Mazzucco, G., \& Rocha, V. (2001). A importância dos valores nas novas formas organizacionais. Revista de Ciências da Administração, 3(5), 63-76.

Mendes, A. (2004). Cultura organizacional e prazer-sofrimento no trabalho: Uma abordagem psicodinâmica. Em Tamayo, A. (Org.), Cultura e saúde nas organizações (pp. 59-76). Porto Alegre: Artmed.

Nassar, N. (2006). Uma parte pelo social. Retirado em 10 de janeiro de 2006, de http://www.portal-rp.com.br/bibliotecavirtual/responsabilidade social/0184.htm 
Oliveira, A. (2001). Cultura organizacional. Em M. Siqueira, S. Junior \& A. Oliveira (Orgs.), Cidadania, justiça e cultura nas organizações: Estudos psicossociais (pp. 165-237). São Bernardo do Campo: UMESP.

Pieron, H. (1966). Dicionário de psicologia (D. B. Cullignan, Trad.). Porto Alegre: Globo.

Pupak, M. (2003). Organizational values. Trabalho apresentado no $X$ Seminario Latino-Iberoamericano de Gestión Tecnológica, Cidade do México.

Robbins, S. (2002). Comportamento organizacional (C. A. Menezes, Trad.). Rio de Janeiro: Livros Técnicos e Científicos.

Sanches, M. (1992). Cultura organizacional: Um paradigma de análise da realidade escolar. Lisboa: GEP/ME.

Schein, E. (1987). Organizational culture and leadership (2 $\left.{ }^{\mathrm{a}} \mathrm{ed}.\right)$. San Francisco: Jossey-Bass.

Senge, P. M. (1999). A dança das mudanças. Rio de Janeiro: Campus.

Silva, N. (2001). As interfaces entre a cultura e aprendizagem organizacional: $O$ caso de uma empresa do setor cerâmico de Santa Catarina. Tese de doutorado não-publicada, Universidade Federal de Santa Catarina.

Silva, N., \& Zanelli, J. (2004). Cultura organizacional. Em J. Zanelli, J. Andrade \& A. Bastos (Orgs.), Psicologia, organizações e trabalho no Brasil (pp. 407-442). Porto Alegre: Artmed.
Stinglhamber, F., Bentein, K., \& Vandenberghe, C. (2004). Congreuence de valeurs et engagement evers l'organisation et le groupe de travail. Psychologie du Travail et des Organizations, 10, 165-187.

Tamayo, A. (1996). Valores organizacionais. Em A. Tamayo e cols. (Orgs.), Trabalho, organizações e cultura (pp. 175-193). São Paulo: Cooperativa de Autores Associados.

Tamayo, A. (1998). Valores organizacionais: Sua relação com a satisfação no trabalho, cidadania organizacional e comprometimento afetivo. Revista de Administração, 33(3), 56-63.

Tamayo, A., Mendes, A. M., \& Paz, M. G. T. (2000). Inventário dos valores organizacionais. Estudos de Psicologia (Natal), 5(2), 289-315.

Terra J. (2000). Gestão do conhecimento; o grande desafio empresarial: Uma abordagem baseada no aprendizado e na criatividade. São Paulo: Negócios.

Weiszflog, W. (Org.) (1998). Michaelis: Moderno dicionário da língua portuguesa. São Paulo: Melhoramentos.

Wilson, R., \& Keil, F. (2001). The MIT encyclopedia of the cognitive sciences. Cambridge: MIT.

\section{Sobre os autores:}

Recebido: 20/12/2007

Última revisão: $11 / 01 / 2010$

Aceite final: 20/01/2010

Ana Luiza Gonçalves da Silva: Psicóloga, Mestre e Doutora em Psicologia pela Universidade Federal de Santa Catarina.

Narbal Silva: Psicólogo, Mestre em Administração e Doutor em Engenharia de Produção pela Universidade Federal de Santa Catarina.

Endereço para correspondência: Ana Luiza Gonçalves da Silva - Av. Buruti, 680 - 605B. 88034-500 Florianópolis/SC. Endereço eletrônico: ana_luiza6@hotmail.com; narbal@chf.ufsc.br. 